Proceedings of the National Conference on Neutron Scattering and the Complementary Methods in the Investigations of the Condensed Phases, Chlewiska 2007

\title{
Liquid Crystalline Polymorphism of 4-Alkyloxybenzylidene-4'-Alkyloxyanilines and Entropic Effects of Their Phase Transitions
}

\author{
J. Godzwon, M.J. Sienkowska and Z. Galewski* \\ Faculty of Chemistry, University of Wrocław \\ 14, Joliot-Curie, 50-383 Wrocław, Poland
}

Dedicated to Professor Jerzy Janik on the occasion of his 80th birthday

This paper summarizes liquid-crystalline polymorphism of the asymmetrical 4-alkyloxybenzylidene-4'-alkyloxyanilines. In this group, containing 121 compounds, 6 types of mesophases were detected: nematic, smectic A, smectic C, smectic B, smectic I, and smectic G. Influence of both alkyl chain length on the type of mesophases and entropic effects of phase transitions are discussed.

PACS numbers: 64.70.M-, 65.40.gd, 64.70.pp

\section{Introduction}

Schiff bases belong to a very popular type of liquid-crystalline compounds. They are easy to synthesize and they have mesophases in convenient temperature range. Unfortunately, due to their sensitivity to moisture they are not applicable in LCD industry. Nevertheless, the first two features are the most important and almost all new ideas in liquid crystal science are tested on new structures containing azomethin groups. 4-Octyloxybenzylidene-4'-cyanoaniline was applied in the first twist-type display [1]. The first banana compound, described ten years ago by Niori, is also a Schiff base [2].

Methoxybenzylidene-4'-methylaniline was described by Bertleff in 1908 [3]. Two other derivatives, 4-methoxybenzylidene-4-methoxyaniline and 4-methoxybenzylidene-4-ethoxyaniline were described by Haberland [4] in 1925 and extensively studied by Weygand and Gabler $[5,6]$ before the World War II. But only compounds with the short alkyl chains were investigated.

*corresponding author; e-mail: ZG@chem.uni.wroc.pl 
Since the 1980s 4-alkyloxybenzylidene- 4 '-alkylanilines were broadly investigated. They were recognized as the molecules with the rich liquid-crystalline polymorphism and today they are employed as most popular standards of mesophases, useful in identification of unknown type of mesophases by miscibility studies.

Similar properties are expected in series with both alkyloxy chains. In spite of very early recognition of this type of compounds, mainly molecules with short alkyl chains were described. Table I shows derivatives described in literature. Recently we have published several articles systematically describing eleven series of 4-alkyloxybenzylidene-4'-alkyloxyanilines [7-11].

TABLE I

4-Alkyloxybenzylidene- $4^{\prime}$-alkyloxyanilines, which were described in literature (०) and were synthesized at Faculty of Chemistry, U.Wr. (ロ ).

\begin{tabular}{|c|c|c|c|c|c|c|c|c|c|c|c|c|c|c|}
\hline $\begin{array}{l}m \\
n\end{array}$ & 1 & 2 & 3 & 4 & 5 & 6 & 7 & 8 & 9 & 10 & 12 & 14 & 16 & 18 \\
\hline 1 & O & ০ & O & Oा & ○ & Oा & a & ○ & घ & घ & घ & & & \\
\hline 2 & Oा & on & On & Oा & ○ा & Oा & a & घ & घ & घ & घ & & & \\
\hline 3 & o & or & o & or & ○ & on & 口 & 口 & ש & च & घ & & & \\
\hline 4 & Oा & on & Oा & Oा & ○ा & ○ा & Oा & on & Oा & Oा & on & & & \\
\hline 5 & On & Oा & On & Oा & ০ & ○ा & घ & घ & घ & घ & घ & & & \\
\hline 6 & Oा & ○ा & on & Oा & ০ & oा & घ & घ & घ & घ & घ & & & \\
\hline 7 & a & oा & on & Oा & oा & Oा & घ & घ & घ & घ & घ & & & \\
\hline 8 & घ & Oा & on & Oा & O & Oा & a & on & 口 & घ & घ & & & \\
\hline 9 & or & or & or & or & on & $\square$ & 口 & $\square$ & 口 & 口 & च & & & \\
\hline 10 & $\square$ & O & o & O & or & घ & $\square$ & $\square$ & $\square$ & or & घ & & & \\
\hline 12 & $\square$ & 口 & or & on & or & o & $\square$ & $\square$ & $\square$ & 口 & घ & & & \\
\hline 14 & & & & & & & & & & & & 0 & & \\
\hline 16 & & ○ & 0 & ○ & 0 & & & & & & & & & \\
\hline 18 & & & o & O & O & & & & & & & & & \\
\hline
\end{tabular}

The main aim of this paper is a detailed analysis of the influence of both alkyloxy chains length on the liquid-crystalline mesomorphism of asymmetrical 4-alkyloxybenzylidene-4'-alkyloxyanilines. Moreover, effects of the destabilization of the present mesophase and entropy of phase transitions between the same mesophases are discussed. This summary was prepared based on our own syntheses and measurements of 121 derivatives.

\section{Influence of the alkyl chain length on the liquid-crystalline polymorphism}

Among 121 synthesized derivatives all compounds exhibit mesomorphic behavior except the 4-propyloxybenzylidene-4'-propyloxyaniline and the 
4-pentyloxybenzylidene- 4 '-pentyloxyaniline. Both compounds are quasisymmetrical and show very high melting temperatures which most probably covers possible liquid-crystalline phase transitions. The mesophases observed and identified for this group are shown in Table II. It is interesting that the data in Table II

TABLE II

Mesophase sequence of 4-alkyloxybenzylidene-4'-alkyloxyanilines.

\begin{tabular}{|c|c|c|c|c|c|c|c|c|c|c|c|}
\hline$m^{n}$ & 1 & 2 & 3 & 4 & 5 & 6 & 7 & 8 & 9 & 10 & 12 \\
\hline 1 & $\mathrm{~N}$ & $\mathrm{~N}$ & $\mathrm{~N}$ & $\mathrm{~N}$ & $\mathrm{~N}$ & $\mathrm{~N}$ & $\mathrm{~N}$ & $\mathrm{~N}$ & $\mathrm{~N}$ & $\mathrm{~N}$ & $\mathrm{~N}$ \\
\hline 2 & $\mathrm{~N}$ & $\mathrm{~N}$ & $\mathrm{~N}$ & $\mathrm{~N}$ & $\mathrm{~N}$ & $\mathrm{~N}$ & $\mathrm{~N}$ & $\mathrm{~N}$ & NACB & NAB & NAB \\
\hline 3 & $\mathrm{~N}$ & $\mathrm{~N}$ & - & $\mathrm{N}$ & $\mathrm{N}$ & $\mathrm{N}$ & $\mathrm{N}$ & $\mathrm{N}$ & NACB & NACB & NAB \\
\hline 4 & $\mathrm{~N}$ & $\mathrm{~N}$ & $\mathrm{~N}$ & $\mathrm{~N}$ & $\mathrm{~N}$ & $\mathrm{~N}$ & $\mathrm{NC}$ & $\mathrm{NCI}$ & NACI & NACB & NACB \\
\hline 5 & $\mathrm{~N}$ & $\mathrm{~N}$ & $\mathrm{~N}$ & $\mathrm{~N}$ & - & $\mathrm{N}$ & $\mathrm{NC}$ & NCIG & NCIG & NACIG & $\mathrm{ACB}$ \\
\hline 6 & $\mathrm{~N}$ & $\mathrm{~N}$ & $\mathrm{~N}$ & $\mathrm{~N}$ & $\mathrm{~N}$ & $\mathrm{~N}$ & $\mathrm{NC}$ & NCIG & NCIG & NACIG & $\mathrm{ACB}$ \\
\hline 7 & $\mathrm{~N}$ & $\mathrm{~N}$ & $\mathrm{~N}$ & $\mathrm{~N}$ & $\mathrm{~N}$ & $\mathrm{NC}$ & $\mathrm{NC}$ & NCI & $\mathrm{NCI}$ & $\mathrm{CI}$ & CI \\
\hline 8 & $\mathrm{~N}$ & $\mathrm{~N}$ & $\mathrm{~N}$ & $\mathrm{~N}$ & $\mathrm{NC}$ & $\mathrm{NC}$ & $\mathrm{NCI}$ & $\mathrm{NC}$ & $\mathrm{NCI}$ & $\mathrm{CI}$ & $\mathrm{CI}$ \\
\hline 9 & $\mathrm{~N}$ & $\mathrm{~N}$ & $\mathrm{~N}$ & $\mathrm{~N}$ & $\mathrm{NC}$ & $\mathrm{NC}$ & $\mathrm{NCI}$ & $\mathrm{NC}$ & $\mathrm{C}$ & $\mathrm{CI}$ & CI \\
\hline 10 & $\mathrm{~N}$ & $\mathrm{~N}$ & $\mathrm{~N}$ & $\mathrm{NC}$ & $\mathrm{NC}$ & $\mathrm{NCI}$ & NCI & NCI & $\mathrm{C}$ & $\mathrm{C}$ & CI \\
\hline 12 & $\mathrm{~N}$ & $\mathrm{~N}$ & $\mathrm{~N}$ & $\mathrm{NC}$ & $\mathrm{NC}$ & NACI & NCI & CI & CI & CI & $\mathrm{C}$ \\
\hline
\end{tabular}

shows an asymmetrical pattern. The alkyloxy chain from the benzylidene's side has larger influence on the amount of mesophases. Six types of mesophases have been recognized: nematic, smectic $\mathrm{A}$, smectic $\mathrm{C}$, smectic I, smectic $\mathrm{B}$, and smectic G. The smectic mesophases are present in derivatives with the longest alkyloxy chains. Most compounds have only one mesophase. For example, 67 derivatives have only nematic mesophase and 4 of them have only smectic C. In case of dimorphic compounds, either nematic and smectic $\mathrm{C}$ or smectic $\mathrm{C}$ and smectic I are present. The first combination is more common (15 compounds) than the second (10 compounds). There are three possible combinations of the trimorphism to appear in this group: NCI, NAB, and ACB. The most characteristic of this family of compounds is the first sequence, which was found among 10 derivatives. The next two sequences appear only for three and for two derivatives, accordingly. This is associated with the fact that smectic $\mathrm{A}$ is an unexpected type of mesophase among the compounds with both alkyloxy chains. Four mesophases were detected for 11 derivatives. The following sequences were observed: NACI (in 2 compounds), NCIG (in 4 compounds), NACB (in 5 compounds). Only 2 derivatives have five mesophases, which appear in a sequence NACIG. These types of morphism, introduced by Demus and Richter [12], are contained in Table III. 
TABLE III

Polymorphism of 4-alkyloxybenzylidene-4'-alkyloxyanilines.

\begin{tabular}{c|c|c|c}
\hline \hline & $\begin{array}{c}\text { Present sequence } \\
\text { of mesophases }\end{array}$ & $\begin{array}{c}\text { Amount of types } \\
\text { of morphism }\end{array}$ & $\begin{array}{c}\text { Amount of cases } \\
\text { of morphism }\end{array}$ \\
\hline Monomorphism & N, C & 2 & 67,4 \\
Dimorphism & NC, CI & 2 & 15,10 \\
Trimorphism & NCI, NAB, ACB & 3 & $10,3,2$ \\
Tetramorphism & NACI, NCIG, NACB & 3 & $2,4,5$ \\
Pentamorphism & NACIG & 1 & 2
\end{tabular}

The comparison of the number of compounds with each type of mesomorphism shows that nematic and tilted smectics $\mathrm{C}$ and $\mathrm{I}$ are the most common phases. Smectics A, B, and G, exist only in few cases and could be even interpreted as a consequence of the fluctuations of the molecules orientations.

The influence of the alkyl chain length on the presence of different types of mesophases is very important. Derivatives with nematic phase are shown in Fig. 1a. All investigated compounds with the shortest chains have nematic phase. The nematic phase is unstable, when the alkyl chains are too long. This phenomenon is observed in compounds with the total length of both alkyloxy chains from 16 to 19 carbon atoms. Figure 1a shows this linear relation. It is interesting to notice that the influence of alkyl chain length on compound's polymorphism is not symmetric, which is most probably the result of the asymmetry of the central azomethin group $-\mathrm{CH}=\mathrm{N}-$.

The second most commonly observed mesophase is smectic C. This phase appears in derivatives where both alkyl chains have more than 12 carbon atoms (Fig. 1b). The stabilization of smectic $\mathrm{C}$ phase is observed with the elongation of alkyl chains.

The presence of the orthogonal smectics A and B in this group of compounds is unexpected (Fig. 1c and d). Smectic A was detected among derivatives with long alkyloxy chains on the benzylidene side (up from nonyloxy) and rather short alkyloxy chains from the aniline side (from ethoxy to hexyloxy). In series with opposite combination of the alkyloxy chains than described above smectic A is observed only in case of 4-hexyloxybenzylidene-4'- dodecyloxyaniline. Most derivatives which have smectic A mesophase have also the smectic $\mathrm{C}$ as well. Only in 3 cases smectic A exists without the smectic $\mathrm{C}$ which could be attributed to the influence of the high melting and recrystallization temperatures, covering possible phase transition SmA-SmC.

The orthogonal smectic B mesophase is observed only in 10 cases. Each compound with this mesophase has smectic A as well. The influence of both alkyloxy chains of a compound is similar. For longer alkyloxy chains on the side of the aniline ring, smectic B changes into smectic I. No derivative was observed 


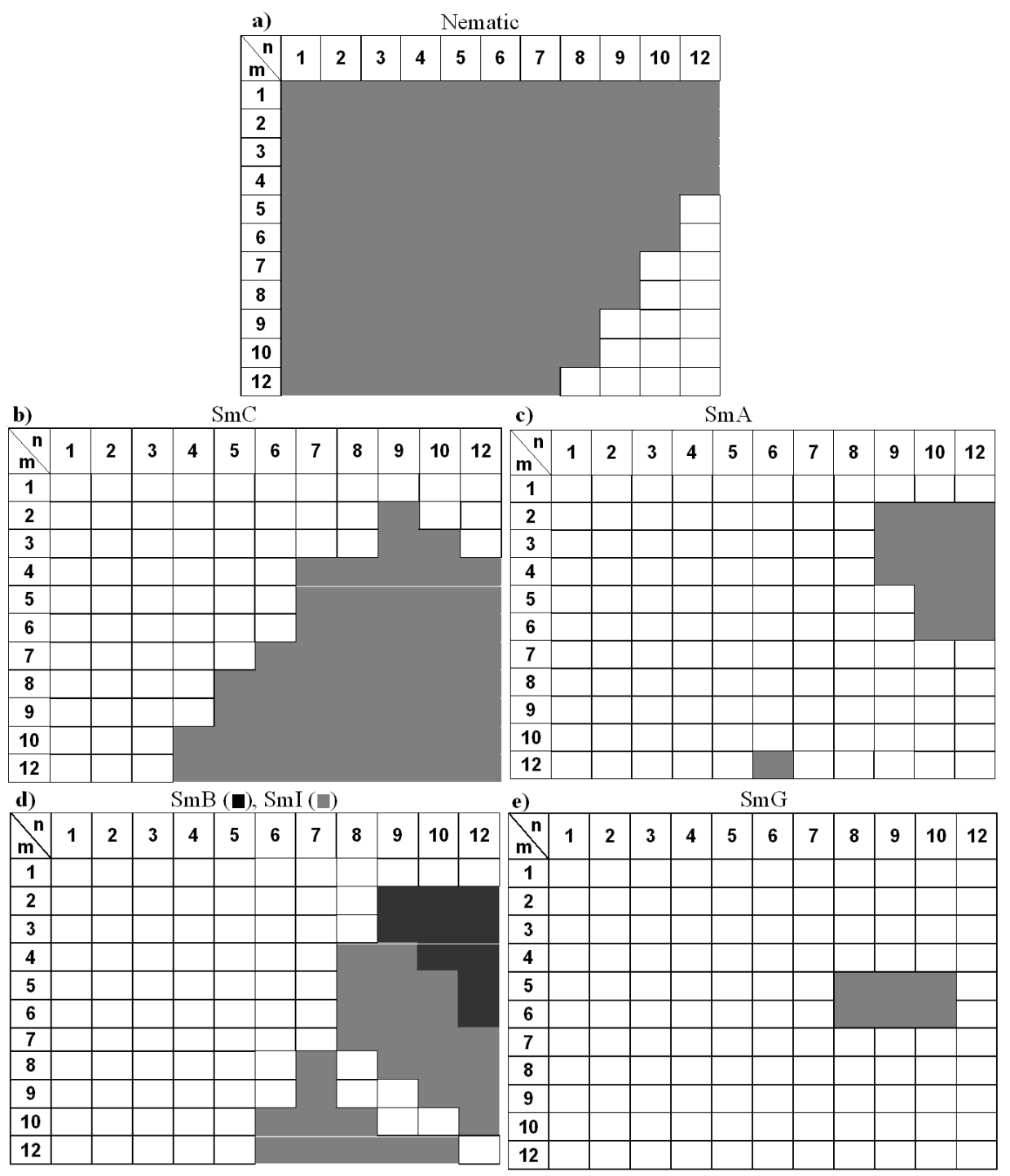

Fig. 1. Influence of the alkyl chain length on the mesophase sequence in 4-alkyloxybenzylidene- $4^{\prime}$-alkyloxyanilines.

with both smectic B and smectic I phases. Also Demus and Richter [12] and Vill [13] did not observe such behavior. However, according to Demus, mesomorphism of FB type (hexamorphism GFBCAN) is possible [12].

Smectic I phase often exists in derivatives, which have both alkyl chains with at least 12 carbon atoms (Fig. 1d). In this case, due to significantly high melting and freezing temperatures in such derivatives where both alkyl chains are of similar length and longer than 12 , it is impossible to observe smectic I phase. 
Only six derivatives from 11 homologues series exhibit smectic G phase (Fig. 1e). This is associated with the relatively low recrystallization and melting temperatures.

Last year Ajeetha et al. [14] described polymorphism of a series of 4-pentyloxybenzylidene- $4^{\prime}$-alkyloxyanilines. Although their results are mostly qualitatively consistent with ours, comparison of temperatures and types of mesophases detected by Ajeetha et al. suggests impurity of their substances. Still, purification of the Schiff bases is particularly difficult. The same series was also described by Gandolfo and Grasso without mesophase identification, in 1983 [15]. Their results are in majority consistent with ours.

\section{Entropic effects of liquid-crystalline phase transitions}

Routine measurements for liquid-crystalline compounds are polarization microscopy (POM) and differential scanning calorimetry (DSC). The latter detects temperatures of phase transitions, which should be consistent with POM results, and their enthalpies. The enthalpy values determine the type of phase transition (I or II order according to Ehrenfest) [16]. Additionally, when the measurements are more precise, they might establish the character of the type of phase transition on quantitative level. For the first time these dependences were presented by Marzotko and Demus in 1980 [17] and more recently by Guillon [18]. According to them, the phase transitions between the mesophases of certain types fall into certain ranges determined on the base of literature data.

However, taking into account the structure of mesophases determined by $\mathrm{X}$-ray measurements $[19,20]$, we can say that most phase transitions between mesophases is of an order-disorder character. Therefore, a more accurate description of a phase transition should be based on the entropy change which corresponds to the level of the disorder [21]. This method of phase transition description is widely used by the Sorai group [22].

Entropies of phase transitions were calculated by using following formula:

$$
\Delta S_{\mathrm{PhR}}=\frac{\Delta H_{\mathrm{PhT}}}{T_{\mathrm{PhT}}},
$$

where enthalpy $\left(\Delta H_{\mathrm{PhT}}\right)$ of phase transitions were taken from the DSC calorimetry (Perkin Elmer DSC7) and temperature of phase transition from the POM and DSC. All measurements were performed by using the identical calorimetric setup. These procedures warrantee relatively high accuracy of results.

First we investigated the transition type nematic-isotropic liquid. According to the most widely used theory, the theory of Maier-Saupe [23], the entropy of this transition should be constant and equal to $3.4 \mathrm{~J} \mathrm{~mol}^{-1} \mathrm{~K}^{-1}$. The results of our investigations for 4-alkyloxybenzylidene-4'-alkyloxyanilines are shown in Fig. 2. The normal distribution of values can be clearly seen, which proves that indeed this transition is related to the loss of one degree of freedom and the value of entropy in the investigated group equals $2.5 \mathrm{~J} \mathrm{~mol}^{-1} \mathrm{~K}^{-1}$. This rule may be considered 
as an analogue of the Trouton rule [21, 24]. Equally interesting are violations of this rule. To begin with, one can observe that the majority of derivatives have the values of entropy increments higher than its mean value in a way both irregular and random. It results from the greater contribution of long alkyl chains to entropy and depends on their length. These matters have been known for many years by groups working on molecular dynamics [25]. From the experimental point of view we can add that the value of entropy increases unexpectedly (a few times) in case of a decay of the nematic phase, when the nematic's temperature range is about 1 $\left(\Delta T_{\mathrm{NI}} \approx 1 \mathrm{~K}\right)$. It concerns other types of transitions as well. We obtained similar results in our previous work [26], although we neglected then the possibility of compound's decomposition due to moisture. In this work we took an extra care of compounds' purity.

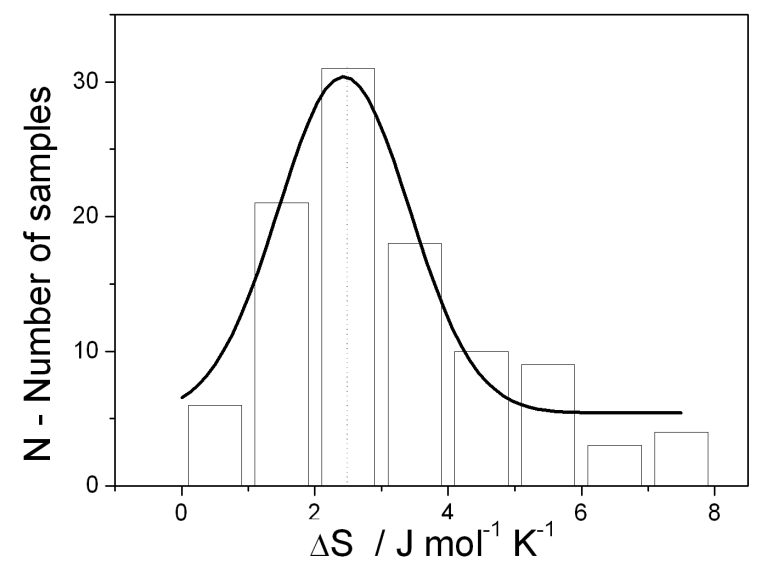

Fig. 2. Statistics of the entropy change in N-Iso phase transition for the 121 compounds belonging to the 4-alkyloxybenzylidene-4'-alkyloxyanilines.

The next type of phase transition is a $\mathrm{SmA}-\mathrm{N}$ (Iso) transition (Fig. 3a). It can be observed that the entropy value is approximately constant and in average equals $1.9 \mathrm{~J} \mathrm{~mol}^{-1} \mathrm{~K}^{-1}$. The influence of alkyl chains, which are of the growing type and of "even-odd" type, is rather insignificant. But the most interesting is the ninefold increase in $\Delta S_{\mathrm{NI}}$ in case of disappearance of the nematic phase. It means that entropy effects are not additive. The loss of degree of freedom of translation gives about $2.5 \mathrm{~J} \mathrm{~mol}^{-1} \mathrm{~K}^{-1}$ entropy decrease, the loss of rotational degree of freedom $-1.9 \mathrm{~J} \mathrm{~mol}^{-1} \mathrm{~K}^{-1}$, whereas the simultaneous loss of both these degrees means the entropy decrease in $18 \mathrm{~J} \mathrm{~mol}^{-1} \mathrm{~K}^{-1}$.

The similar dependences were found for the $\mathrm{SmC}-\mathrm{N}$ (Iso) transition (Fig. 3b). The average values of entropy increments for these transitions, calculated from our measurements, are $4.7 \mathrm{~J} \mathrm{~mol}^{-1} \mathrm{~K}^{-1}$ and $25.9 \mathrm{~J} \mathrm{~mol}^{-1} \mathrm{~K}^{-1}$, accordingly. These values are higher than in the previously described types of transitions as these transitions appear for derivatives with longer alkyl chains. Also in this case the in- 

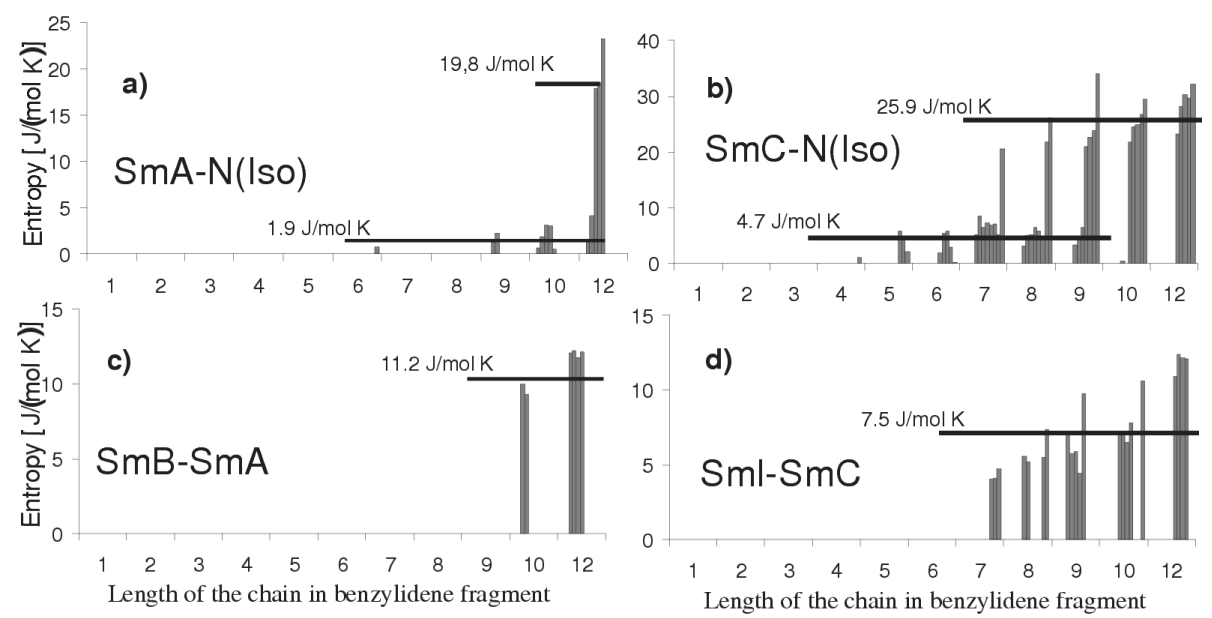

Fig. 3. Values of entropy of 4-alkyloxybenzylidene-4'-alkyloxyanilines for the phase transition: (a) SmA-N(Iso), b) SmC-N(Iso), (c) SmB-SmA, (d) SmI-SmC.

fluence of alkyl chains on entropy and the clear separation of all entropy values into two groups may be observed. The lower values are in average of $4.7 \mathrm{~J} \mathrm{~mol}^{-1} \mathrm{~K}^{-1}$ and describe the $\mathrm{SmC}-\mathrm{N}$ transition in case where $\mathrm{SmC}-\mathrm{N}$ and $\mathrm{N}-\mathrm{Iso}$ are both well defined. If the temperature range of the nematic decreases to $1 \mathrm{~K}$ or if the nematic entirely disappears, the average values of entropy increment raise five times up to the mean value of $25.9 \mathrm{~J} \mathrm{~mol}^{-1} \mathrm{~K}^{-1}$.

The last investigated transition type is the transition SmB-SmA (Fig. 3c). We measured its entropy in case of six compounds and obtained approximately constant result of $11.2 \mathrm{~J} \mathrm{~mol}^{-1} \mathrm{~K}^{-1}$. If these orthogonal smectics (SmA, SmB) are replaced with titles analogues $(\mathrm{SmI}, \mathrm{SmC})$ the mean entropy value shifts slightly to $7.5 \mathrm{~J} \mathrm{~mol}^{-1} \mathrm{~K}^{-1}$ (Fig. 3d). Considering rather regular influence of both alkyl chains we can say that the entropy changes in these both transitions are of a similar type.

\section{Conclusions}

1. The elongation of alkyl chain contributes to the presence of smectic phases and destabilization of nematic phase.

2. Nematic and tilted smectics: smectic C and I are typical of 4-alkyloxybenzylidene-4'-alkyloxyanilines. The following type sequences were found: $\mathrm{N}$, C, NC, CI, NCI, NAB, ACB, NACI, NACIG, NCIG, and NACB.

3. The presence of orthogonal smectics ( $\mathrm{SmA}$ or $\mathrm{SmB}$ ) in 14 derivatives among 121 compounds is unusual.

4. Only six derivatives from 11 homologues series exhibit smectic G phase.

5. All observed phase transitions are the I-order except the phase transition $\mathrm{SmA-SmC}$, which in few cases is the II-order. 
The entropies of phase transition nematic-isotropic show the normal distribution with the most probable value $2.5 \mathrm{~J} \mathrm{~mol}^{-1} \mathrm{~K}^{-1}$.

6. The value of entropy of the phase transition nematic-isotropic increases unexpectedly (a few times) in case of a decay of the nematic phase, when the nematic's temperature range is about $1\left(\Delta T_{\mathrm{NI}} \approx 1 \mathrm{~K}\right)$.

7. Entropies of the phase transitions $\mathrm{SmA}-\mathrm{SmB}$ and $\mathrm{SmC}-\mathrm{SmI}$ show weak dependence on the alkyl chain length.

\section{References}

[1] M. Schadt, W. Helfrich, Appl. Phys. Lett. 18, 127 (1971).

[2] T. Niori, T. Sekane, J. Watanabe, T. Furukawa, H. Takezoe, J. Mater. Chem. 6, 1231 (1996).

[3] V. Bertleff, Dissertation, Halle, 1908.

[4] H. Haberland, Berichte 58, 2652 (1925).

[5] C. Weygand, R. Gabler, J. Prakt. Chemie N.F. 151, 215 (1938).

[6] C. Weygand, R. Gabler, J. Prakt. Chemie N.F. 155, 332 (1940).

[7] J. Godzwon, M.J. Sienkowska, Z. Galewski, Liq. Cryst. 34, 911 (2007).

[8] J. Godzwon, M.J. Sienkowska, Z. Galewski, Phase Transit. 80, 217 (2007).

[9] J. Godzwon, M.J. Sienkowska, Z. Galewski, Phase Transit 80, 1 (2007).

[10] J. Godzwon, M.J. Sienkowska, Z. Galewski, J. Mol. Struc. 844-845, 259 (2007).

[11] J. Godzwon, M.J. Sienkowska, Z. Galewski, in: Conf. Proc., XVI Conf. on Liquid Crystals, Stare Jabtonki (Poland) 2005, Eds. P. Perkowski, Z. Raszewski, J. Zieliński, Publishing House Military University of Technology (MUT), Warsaw 2005, p. 29.

[12] D. Demus, L. Richter, Textures of Liquid Crystals, VEB Verlag, Leipzig 1980.

[13] V. Vill, LiqCryst4.6 database, LCI, Fujitsu 2005.

[14] N. Ajeetha, V.G.K.M. Pisipati, M. Ramakrishna Nanchara Rao, P.V. Datta Prasad, Mol. Cryst. Liq. Cryst. 457, 3 (2006).

[15] C. Gandolfo, D. Grasso, Termochim. Acta 65, 239 (1983).

[16] P. Papon, J. Leblond, P.H.E. Meijer, The Physics of Phase Transitions, 2nd ed., Springer Verlag, Berlin 2006.

[17] D. Marzotko, D. Demus, in: Liquid Crystals, Proc. Int. Conf., Pramana, Ed. S. Chandrasekhar, Indian Academy of Science, Bangalore 1973, Suppl. No. 1, p. 189.

[18] D. Guillon, in: Handbook of Liquid Crystals, Eds. D. Demus, J. Goodby, G.W. Gray, H.-W. Spiess, V. Vill, Wiley-VCH, Weinheim 1998, Vol. 2A, p. 23.

[19] A.J. Leadbetter, in: The Molecular Physics of Liquid Crystals, Eds. G.R. Luckhurst, G.W. Gray, Academic Press, London 1979, p. 285.

[20] J.M. Seddon, in: Handbook of Liquid Crystals, Eds. D. Demus, J. Goodby, G.W. Gray, H.-W. Spiess, V. Vill, Wiley-VCH, Weinheim 1998, p. 635.

[21] P.W. Atkins, Physical Chemistry, 6th ed., Oxford University Press, Oxford 1998.

[22] K. Saito, M. Ikeda, M. Sorai, J. Therm. Analysis Calorimetry 70, 345 (2002). 
[23] G.R. Luckhurst, in: The Molecular Physics of Liquid Crystals, Eds. G.R. Luckhurst, G.W. Gray, Academic Press, 1979.

[24] F.T. Trouton, Philos. Mag. 18, 54 (1884).

[25] R. Berardi, L. Muccioli, C. Zannoni, Chem. Phys. Chem. 5, 104 (2004).

[26] Z. Galewski, M. Sienkowska, A. Hofmańska, Proc. SPIE 4759, 85 (2002). 